\title{
Signaux de la coopération $T-B$ et production d'anticorps
}

\section{Yolande Richard Pierre Galanaud}

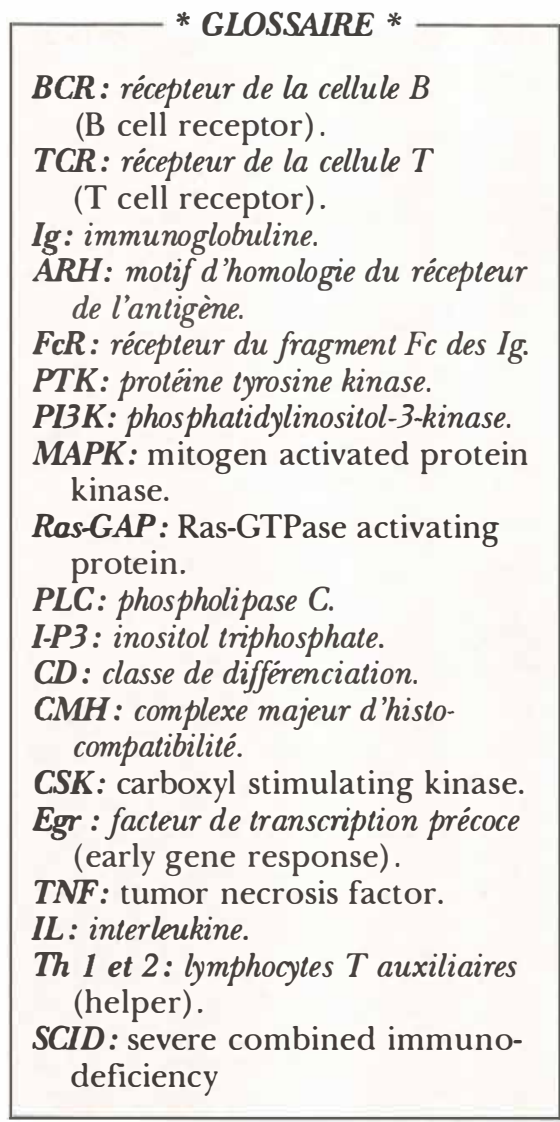

Y. Richard: chargée de recherche au Cnrs. P. Galanaud: professeur d'immunologie, direc teur de l'U. 131 de l'Inserm. Inserm U.131, Institut Paris Sud sur les cytokines, 32, rue des Carnets, 92140 Clamart, France.

La réponse immunitaire $B$ repose sur des interactions cellulaires entre lymphocyte $B$ et lymphocyte $T$ organisées dans l'espace, mais aussi dans le temps, dans le cadre d'un dialogue bidirectionnel. Le lymphocyte $B$ franchit une série d'étapes successives: activation, déclenchée par l'interaction entre l'antigène et son récepteur spécifique (BCR), conduisant à l'expression de récepteurs des signaux de coopération $\mathrm{T} / \mathrm{B}$; prolifération, permettant l'expansion des clones activés ; éventuellement, commutation de classe ; différenciation terminale en cellule produisant des quantités importantes d'une immunoglobuline destinée à l'exportation. L'activation permet l'internalisation de l'antigène qui sera apprêté et présenté par les molécules de classe II du CMH au lymphocyte $\mathrm{T}$ auxiliaire. Une fois activé, celui-ci va délivrer les signaux de coopération cellulaire, indispensables à la réponse $\mathrm{B}$, transmis à la fois par contact cellulaire direct et par des médiateurs paracrines, les cytokines.

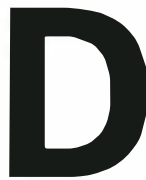
importants progrès on été accomplis en matière de réponse lymphocytaire B (figure 1) et notamment dans les domaines concernant: (1) le BCR et la signalisation spécifique d'antigène; (2) le rôle des molécules membranaires intervenant dans les interactions T-B directes et, (3) celui des cytokines influençant les différentes étapes de la coopération T-B.

\section{$B C R$ et activation des lymphocytes B}

Composition du BCR et analogies avec le TCR

Un des éléments essentiels à l'induction de la réponse $B$ à l'antigène est l'expression d'un récepteur spécifique: BCR ( $B$ cell receptor). Celui-ci présente de nombreuses analogies, tant dans sa composition que dans son mode de fonctionnement, avec le récepteur T de l'antigène (TCR) [1]. Pour le BCR, l'unité de reconnaissance de l'antigène est constituée d'un tétramère covalent comportant deux chaînes lourdes et deux chaînes légères d'immunoglobulines. Reconnu sous sa forme native, l'antigène se lie aux régions variables des immunoglobulines membranaires définissant deux sites d'interaction par molécule d'immunoglobuline. Deux hétérodimères covalents $\alpha / \beta$, essentiels à l'expression en surface des immunoglobulines, à l'internalisation du BCR et de l'antigène, et à la transmission de signaux d'activation vers le noyau, s'associent à ces immunoglobulines membranaires [2]. Les protéines $\alpha$ et $\beta$ sont les homologues humains des produits des gènes murins $m b l$ et $B 29$ antérieurement clonés. Ces deux pro- 


\section{RÉFÉRENCES}

1. Borst J, Brouns GS, De Vries E, Verschuren MCM, Mason DY, Van Dongen JJM. Antigen receptors on $\mathrm{T}$ and $\mathrm{B}$ lymphocytes: parallels in organization and function. Immunol Rev 1993; 132 : 49-84.

2. Kwang-Myong $\mathrm{K}$, Gottfried $\mathrm{A}$, Weiser $\mathrm{P}$, Reth M. Signalling function of the B-cell antigen receptors. Immunol Rev 1993; 132: $125-46$.

3. Lankester AC, Van Schijndel GMW, Frommé J, Cordell JL, Van Lier RAW, Van Noesel CJM. Evidence for a direct physical interaction of membrane IgM, IgD, and IgG with the $B 29$ gene product. J Immunol 1994 ; 152: 2157-62.

4. Cambier JC, Bedzyk W, Campbell K, Chien N, Friedrich J, Harwood A, Jensen $W$, Pleiman C, Clark MR. The B-cell antigen receptor: structure and function of primary, secondary, tertiary and quarternary components. Immunol Rev 1993; 132: 85-106.

5. Takata M, Sabe $H$, Hata A, Inazu T, Homma Y, Nukada T, Yamanura H, Kurosaki T. Tyrosine kinases Lyn and Syk regulate $B$ cell receptor-coupled $\mathrm{Ca}^{++}$mobilization through distinct pathways. EMBO J 1994 ; 13 : 1341-9.

6. Sanchez M, Misulovin Z, Burkhardt AL Mahajan S, Costa T, Franke R, Bolen JB, Nussenzweig M. Signal transduction by immunoglobulin is mediated through Ig $\alpha$ and Ig $\beta$. J Exp Med 1993; 178: 1049-55.

7. Clark MR, Campbell KS, Kazlauskas A, Johnson SA, Hertz M, Potter TA, Pleiman C, Cambier JC. The B cell antigen receptor complex : association of $\operatorname{Ig} \alpha$ and $\operatorname{Ig} \beta$ with distinct cytoplasmic effectors. Science 1992; 258: 123-6.

8. Yamamoto $\mathrm{T}$, Yamanashi $\mathrm{Y}$, Toyoshima $\mathrm{K}$. Association of Src-family kinase Lyn with Bcell antigen receptor. Immunol Rev 1993; 132: 187-206

9. Flaswinkel H, Reth M. Dual role of the tyrosine activation motif of the Ig $\alpha$ protein during signal transduction via the $\mathrm{B}$ cell antigen receptor. $E M B O J 1994 ; 13: 83-9$.

10. Yamanashi Y, Fukui Y, Wongsasant B, Kinoshita Y, Ichimori Y, Toyoshima K, Yamamoto T. Activation of Src-like protein-tyrosine kinase Lyn and its association with phosphatidylinositol 3-kinase upon B-cell antigen receptor-mediated signaling. Proc Natl Acad Sci USA 1992; 89: 1118-22.

11. Gold MR, Crowley MT, Martin GA, McCormick F, De Franco AL. Targets of B lymphocyte antigen receptor signal transduction include the p21 ras GTPase-activating protein (GAP) and two GAP-associated téines, N-glycosylées, de masse moléculaire respective 47 et $37 \mathrm{kDa}$ présentent chacune un domaine extracellulaire de type Ig-like, ainsi qu'un résidu cystéine impliqué dans la formation des hétérodimères $\alpha / \beta$ covalents. Les zones hydrophiles des domaines transmembranaires de $\alpha$ et $\beta$ sont nécessaires au transport à la membrane du BCR, celles de la chaîne $\beta$ seraient en outre directement responsables des interactions avec les immunoglobulines membranaires [3]. Les hétérodimères $\alpha / \beta$ peuvent s'associer aussi bien aux IgM qu'aux autres isotypes. Ils présentent alors des différences de taille qui résultent uniquement de glycosylations différentes, notamment de la chaîne $\beta$ [3]. De telles variations de glycosylation ont également été décrites entre les composants CD3 s'associant, soit au TCR $\alpha \beta$, soit au TCR $\gamma \delta$ [1]. En parfait accord avec ce qui est décrit pour leurs homologues du TCR, les produits des gènes $m b 1$ et $B 29$ sont transcrits et traduits avant même l'expression des chaînes $\mu$. L'expression membranaire de ces hétérodimères est ensuite stable du stade pré-B au stade plasmocytaire $[1,4]$.

\section{Signalisation via le BCR}

La stimulation du lymphocyte B via le BCR, comme celle via le TCR, induit de nombreux événements précoces de phosphorylation qui font intervenir plusieurs types de kinases [2, 4]. L'association à ces kinases implique notamment les motifs ARH1* présents dans les régions cytoplasmiques de $\alpha$ et $\beta$ et similaires à ceux décrits pour les chaînes $\gamma, \delta, \varepsilon, \zeta$ du CD3, $\beta$ du FcREI et $\gamma$ du FcR $\gamma$ IIA $[1,4]$. Malgré ces similitudes, chacune des chaînes $\alpha, \beta$ semble responsable de la mise en jeu de signaux précoces différents et complémentaires [5] (figure 2).

La chaîne $\alpha$ semble jouer un rôle prédominant dans la signalisation précoce [6] via sa phosphorylation par les phosphotyrosine kinases (PTK) de la famille Src alors que la chaîne $\beta$ serait plus fortement phosphorylée sur des résidus sérine et thréonine [7] et interagit, sous sa forme phosphory-

\footnotetext{
* Les motifs $A R H$ (antigen receptor homology) sont des motifs conservés permettant l'ancrage des protéine kinases sur les récepteurs des antigènes, de structure: $D / E-X 7-D / E-X 2-Y-X 2-L / I-X 7-Y-X 2-L / I$, où $D=A s p, E=G l u, L$-leu, I=ileu, $Y^{\prime}=$ Tyr et $X=$ $n$ 'importe quel acide aminé.
}

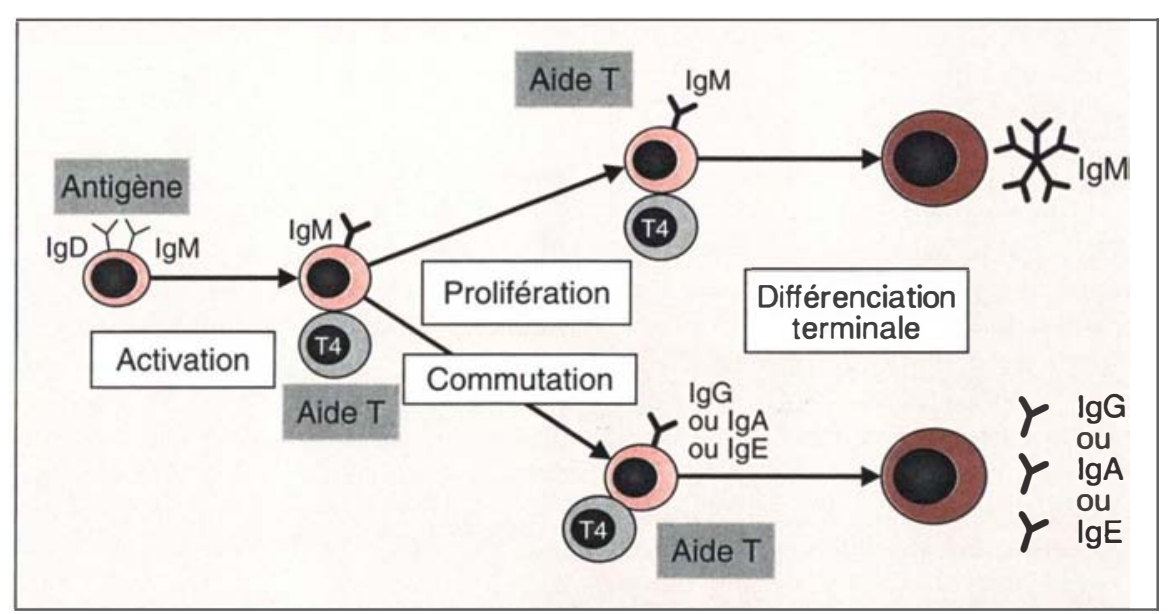

Figure 1. Les étapes de la réponse lymphocytaire $B$. Le lymphocyte $B$ naïf, exprimant à sa surface $\lg M$ et $\lg D\left(s \lg M^{+}-s / g D^{+}\right)$reconnaît spécifiquement $I^{\prime}$ antigène via le BCR. Le lymphocyte $B$ activé (slg $\left.M^{+} s / g D^{-}\right)$exprime de novo les molécules $B 7.2$ et B7.1, produit des cytokines (TNF $\alpha, I L 6, I L 4, I L 10)$ et exprime plus fortement les molécules du CMH de classe II, CD40, CD11a/CD18 et CD54. Les lymphocytes $C D 4^{+}$en interagissant avec le lymphocyte $B$ activé via les interactions TCR-CD4/Ag-CMH,CD28/B7, CD40-L/CD40, ICAM1/LFA1 et en produisant, de façon polarisée, des cytokines (IL2, IL4) induit la prolifération clonale des lymphocytes $B$ et la production $d^{\prime} l g M$. Les interactions CD40/CD40-L en présence de différentes cytokines (IL4, IL 10) induisent aussi la commutation vers la production $d^{\prime} I g E, d^{\prime} l g G$ ou $d^{\prime} I g A$ respectivement. 
lée, avec une phosphatidylinositol-3 kinase (PI3K) [4]. Les Src-PTK (Lyn, Fyn, Blk et Lck) seraient associées, sous forme inactive, à la chaîne $\alpha$ et activées par la liaison de l'antigène au BCR $[2,8]$. Cette activation se traduit par leur autophosphorylation, la phosphorylation des dimères $\alpha / \beta$ [9] et celle de kinases cytoplasmiques telles que MAPK (mitogen-activated protein kinase), PI3K [10] et GAP (RasGTPase activating protein) [11].

Une autre PTK cytoplasmique, PTK 72, homologue de Syk (lympho- cytes B de porc) et de ZAP 70 (lymphocytes T murins, $m / s n^{\circ} 10$, vol. 10 , p. 1038 et $n^{\circ} 2$, vol. 11, p. 268) intervient lors des phases précoces de phosphorylation [4, 12]. Différentes données expérimentales suggèrent que la PTK72 pourrait être associée au BCR, via les IgM, avant stimulation par l'antigène. Celle-ci provoquerait des changements conformationnels du BCR induisant la rupture de la liaison PTK72/chaîne $\mu$, le relargage et l'activation de PTK72 dans le cytoplasme [4]. Cette dernière serait res- ponsable de l'activation d'une phospholipase C, PLC $\gamma 2$ [13], qui règle la formation d'inositol-phosphates et de diacylglycérol, qui à leur tour entraînent, respectivement, une augmentation du calcium cytosolique et l'activation de PKC comme cela a été décrit pour d'autres récepteurs $(\mathrm{m} / \mathrm{s}$ $n^{\circ} 10$, vol. 8, p. 1097). Bien que Syk et Lyn puissent activer une PI3K, l'utilisation de lignées murines déficientes pour les PTK a montré que le gène syk jouait un rôle essentiel dans la production d'IP3 et de $\mathrm{Ca}^{2+}$ alors que

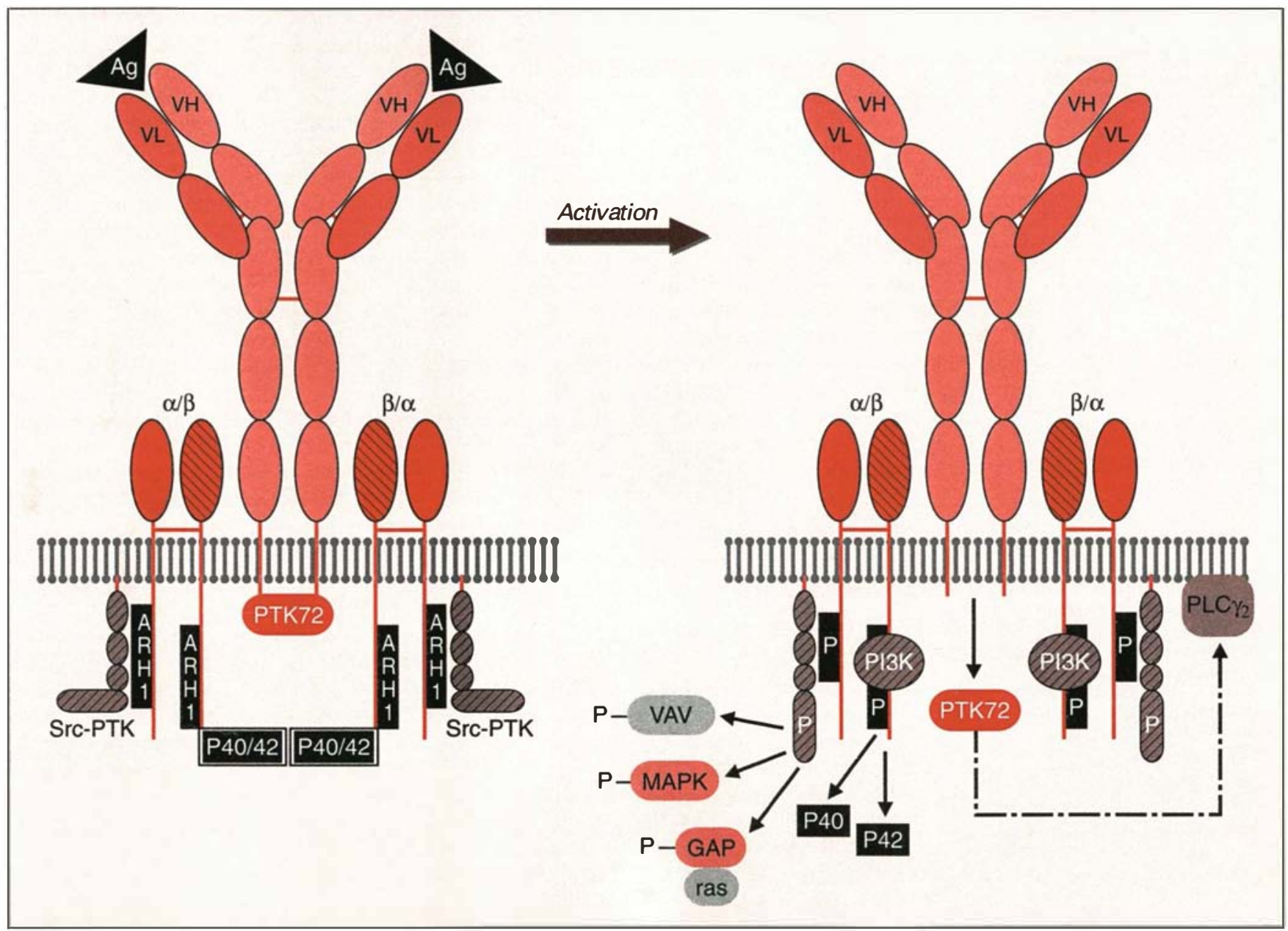

Figure 2. Événements précoces de phosphorylation après liaison de l'antigène au BCR. Lorsque les lymphocytes $B$ sont au repos (naïfs ou mémoires), les immunoglobulines de surface (IgM, IgG, IgA ou IgE) forment un complexe fonctionnel avec les dimères $\alpha \beta$. Ces complexes sont orientés: $c^{\prime}$ est la chaîne $\beta$ qui est la plus proche des immunoglobulines; elle lie, dans son domaine cytoplasmique, la protéine p40/42 de fonction encore inconnue. La chaîne $\alpha$ interagit avec les phosphotyrosine kinases (PTK) de la famille Src tandis qu'une PTK de 72 kDa (PTK72) s'associerait aux chaînes lourdes (VH) des immunoglobulines. Après liaison de l'antigène (1) les Src-PTK sont activées, s'autophosphorylent et phosphorylent les dimères $\alpha \beta$. La phosphorylation de la chaîne $\beta$ lui permet de lier une phosphatidylinositol-3 kinase (PI3K) qu'elle active à son tour, et de relâcher la protéine $040 / 42$; (2) l'activation de la PTK72 est suivie de celle de la phospholipase C PLCY2 qui conduit à la production d'inositol trisphosphate tandis que l'activation des Src-PTK est suivie de l'activation de mitogen activated protein kinase (MAPK), de Ras-GTPases-activating proteins (Ras-GAP), des p62 et p190 GAP-associated proteins et celle du proto-oncogène VAV. 


\section{RÉFÉRENCES}

12. Hutchcroft JE, Harrison ML, Geahlen RL. Association of the 72-kDa protein-tyrosine kinase PTK72 with the B cell antigen receptor. I Biol Chem $1992 ; 267: 8613-9$

13. Coggeshall KM, McHugh JC, Altman A. Predominant expression and activationinduced tyrosine phosphorylation of phospholipase C $\gamma 2$ in B lymphocytes. Proc Natl Acad Sci USA 1992; 89: 5660-4.

14. Gulbins E, Langlet C, Baier G, Bonnefoy Berard N, Herbert E, Altman A, Coggeshal KM. Tyrosine phosphorylation and activation of Vav GTP/GDP exchange activity in antigen receptor-triggered B cells. I Immunol $1994 ; 152 ; 2123-9$.

15. Yamanashi $Y$, Okada $M$, Semba $T$, Yamori T, Umemori H, Tsunasawa $S$, Tovoshima K, Kitamura D., Watanabe T. Identification of HSl protein as a major substrate of protein-tyrosine kinase(s) upon B-cell antigen receptor-mediated signaling. Proc Nall Acad Sci USA 1993 ; 90 : 3631-5.

16. Justement LB, Campbell KS, Chien NS, Cambier JC. Regulation of $B$ cell antigen receptor signal transduction and phosphorylation by CD45. Science $1991 ; 252$ : 1839-42.

17. Clark EA. CD22, a B cell-specific receptor, mediates adhesion and signal transduction. I Immunol 1993; 150:4715-8.

18. Carter RH, Tuveson DA, Park DJ Rhee SG, Fearon DT. The CD19 complex of $\mathrm{B}$ lymphocytes. Activation of phospholi pase $C$ by a protein tyrosine kinase-dependent pathway that can be enhanced by the membrane IgM complex. I Immunol 1991. membrane $1 \mathrm{~g}$

19. Leprince $\mathrm{C}$, Drave $\mathrm{KE}$, Geahlen Ledbetter IA, Clark EA. CD22 associates with the human surface IgM/B cell antigen receptor complex. Proc Natl Acad Sa USA $1993 ; 90: 3236-40$.

20. Schulte RJ, Campbell MA, Fischer WH Sefton BM. Tyrosine phosphorylation of CD22 during B cell activation. Scrence 1992 $258: 1001-4$.

21. Pesando JM, Bouchard LS, McMaster BE. CD19 is functionally and physically associated with surface immunoglobulin. J Exp Med 1989; 170: 2159-64

22. Carter RH, Fearon DT. CD19: lowering the threshold for antigen receptor stimulation of B lymphocytes. Srience 1992; 256: 105-7.

23. Van Noesel CJM, Lankester AC, Van Schijndel GMW, Van Lier RAW. The CR2/CD19 complex on human B cells contains the src-family kinase Lyn. Int Immu nol $1993 ; 5: 699-705$. l'absence de gène lyn inhibe la mobilisation calcique sans affecter la production d'IP3 [5]. La stimulation du BCR induit aussi l'activation de sérine/thréonine protéine kinases [7], du proto-oncogène Vav [14] et des p62 et p190 GAP-associated proteins [11]. Les formes activées de Vav, de p62 et de p190 règlent l'activité de p2 $1^{\text {ras }}$ et/ou des événements immédiatement en aval de $\mathrm{p} 21^{\text {ras }}\left(\mathrm{m} / \mathrm{s} n^{\circ} 1\right.$, vol. 1), p. 125) $[4,11,14]$.

A terme, l'ensemble de ces processus conduit à la phosphorylation et à l'activation de différents facteurs de transcription (Egr-1, Egr-2, c-Fos, cMyc) [2, 4] réglant potentiellement la production de cytokines par le lymphocyte B et l'expression de molécules de surface importantes pour la présentation de l'antigène aux lymphocytes $\mathrm{T}$ ou pour les interactions $\mathrm{T}$ B. Il faut aussi noter la phosphorylation sur des résidus tyrosines d'une protéine cytoplasmique HSI (p75) qui présente des caractéristiques de facteur de transcription [8, 15] et pourrait transmettre directement des signaux au niveau nucléaire.

Le retour à l'état non activé est nécessaire pour que le lymphocyte soit capable de répondre à une nouvelle stimulation antigénique. Au moins deux enzymes interviendraient dans ce phénomène: la PTK CSK (C-terminal Srr kinase) et la molécule CD45 (figure 3). La phosphorylation des régions carboxy-terminales des SrcPTK par CSK entraîne leur inactivation [4]. Par ailleurs, grâce à ses deux domaines phosphatases cytoplasmiques, la molécule CD45 (forme CD45RA sur le lymphocyte B) induirait une déphosphorylation, notamment des chaînes $\alpha$, $\beta$ et des Src-PTK [16]. Il faut noter que ni CSK ni CD45 ne sont capables de régler l'activité de PTK72 [4]. Les mécanismes par lesquels les activités enzymatiques de CSK et CD45 sont induites restent à définir.

\section{Molécules jouant le rôle de corécep- teurs du BCR}

Dans le cas du TCR, les antigènes CD4 et/ou CD8 jouent un rôle important de molécules délivrant un cosignal d'activation (figure 3). Un rôle potentiel identique pourrait être dévolu à deux antigènes spécifiques des lymphocytes B: CD22 [17] et le complexe CD19/CD21 [18]. Comme pour les corécepteurs du TCR, le pontage de CD19 seul inhibe le signal d'activation transmis via le BCR, alors que le pontage simultané de CD19 et du BCR amplifie la réponse relayée par le BCR seul [18]. CD22 est une molécule exprimée dans le cytoplasme des cellules pro- et pré-B et à la surface des lymphocytes $B$ mûrs. L'expression de CD22 suit l'expression des immunoglobulines de surface et notamment celle des $\operatorname{IgD}$. En effet, l'intensité de l'expression de CD22 est forte dans la zone du manteau où les lymphocytes $\mathrm{B}$ coexpriment $\operatorname{Ig} M$ et $\operatorname{IgD}$, alors que les lymphocytes B activés des centres germinatifs cessent d'exprimer IgD et CD22 [18]. De plus, seuls les lymphocytes $\mathrm{CD} 22^{+}$répondent à une stimulation par l'antigène, ce qui suggère une association entre CD22 et BCR. Une telle association physique et fonctionnelle a été indépendamment démontrée par les travaux de C. Leprince [19] et de R.J. Schulte [20]. Globalement, leurs résultats montrent la coprécipitation de CD22, des $\operatorname{Ig} M$ et des dimères $\alpha / \beta$, la présence au sein de ce complexe de la protéine PTK72, et la phosphorylation rapide de CD22 lors de la stimulation via le BCR. La présence d'un motif $\mathrm{ARH} 1$ dans la région cytoplasmique de CD22 pourrait permettre l'association de molécules CD22 phosphorylées à la PTK 72 [17]. Là encore, se pose la question du ligand physiologique de CD22. Après clonage du gène codant pour la molécule CD22, l'utilisation de transfectants et de protéine de fusion a permis d'identifier deux ligands: la molécule CD75 exprimée par certains lymphocytes B activés présents dans les centres germinatifs et surtout la molécule CD45RO exprimée par les lymphocytes T mémoires.

CD 19 est une des molécules du lymphocyte $\mathrm{B}$ exprimée le plus précocement dans la différenciation $B$ et dont l'expression est maintenue jusqu'au stade préplasmocytaire. L'expression de CD19 est en effet retrouvée sur des progéniteurs très précoces $\mathrm{CD} 34^{+}$mais aussi sur des progéniteurs bipotentiels exprimant CD19 en association à des marqueurs spécifiques des lymphocytes $\mathrm{T}$ tels que CD2 et CD7. De nombreux effets fonctionnels suggèrent une associa- 


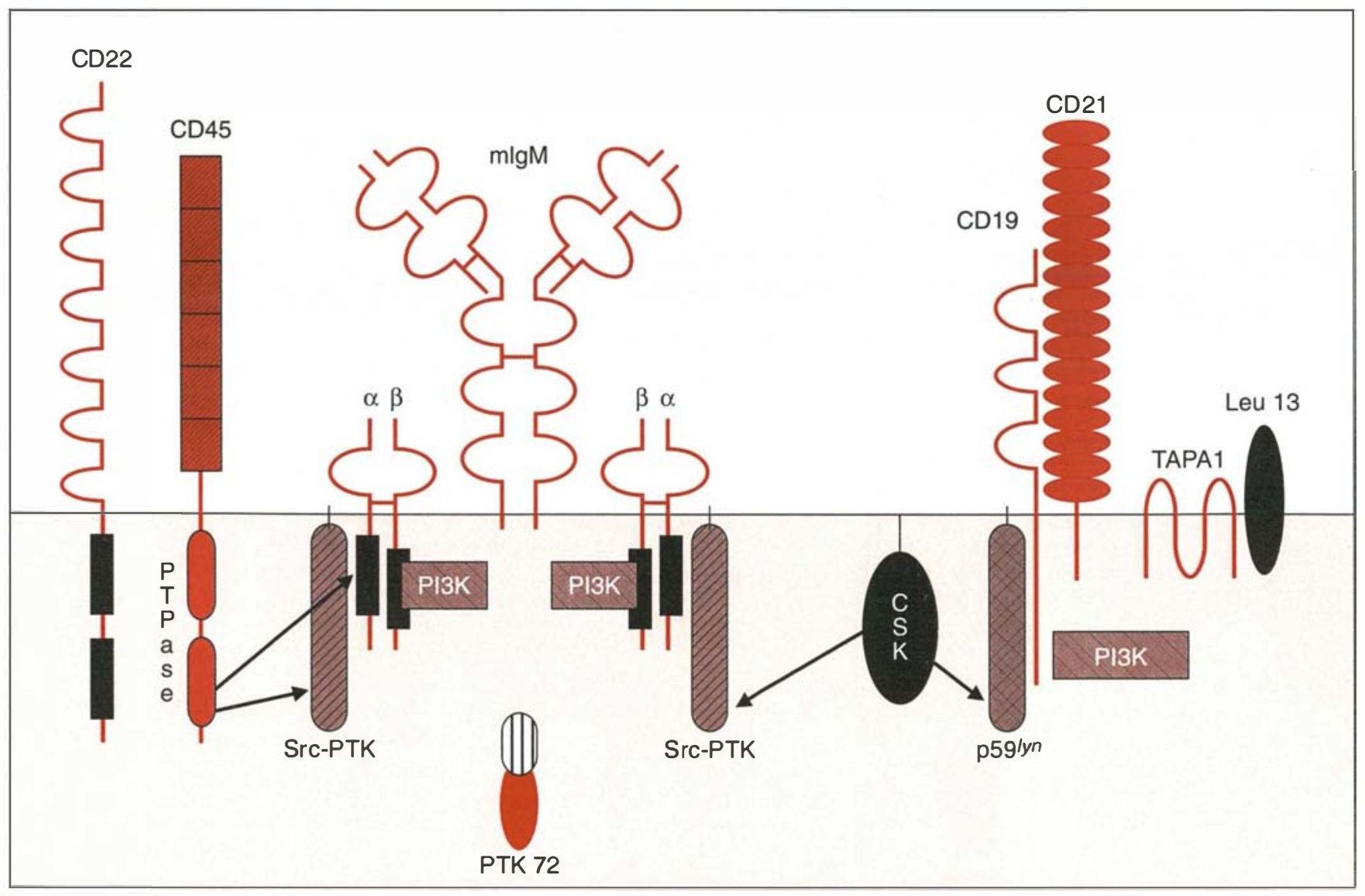

Figure 3. Molécules régulatrices de l'activation du BCR. Outre les dimères $\alpha \beta$ associées directement aux immunoglobulines, d'autres molécules membranaires peuvent s'associer transitoirement au BCR et influencer la transduction du signal antigénique. C'est le cas du complexe CD19/CD21, incluant aussi les molécules TAPA-1 (CD81) et leu 13, qui, via l'activation d'une PI3K et/ou de la PTK p59'vn, peuvent amplifier la réponse à I'antigène. De la même façon, la molécule CD22 amplifie cette réponse en stimulant l'activation de la PTK72. La molécule CD45 et la kinase CSK règlent négativement l'activation des Src-PTK et des dimères $\alpha \beta$, permettant le retour à l'état basal. En absence d'antigène, la stimulation de CD19 ou de CD22 peut conduire à l'anergie du lymphocyte $B$.

tion au BCR: (1) les IgM de surface (sIgM) et CD19 sont coexprimés à la surface des lymphocytes B mûrs [21], (2) l'engagement de la molécule CD19 induit un accroissement des substrats cytoplasmiques phosphorylés sur des tyrosines, une mobilisation de $\mathrm{Ca}^{2+}$ intracellulaire, et une production d'IP3 [18] et diminue les quantités d'antigène nécessaires à l'activation des lymphocytes B [22].

Malgré cette synergie entre les signaux délivrés via CD19 et BCR, l'engagement de CD19, au contraire de celui du BCR, ne module ni l'expression de c-Myc ni celle des antigènes HLA de classe II. Des données récentes montrent que l'engagement du BCR induit la phosphorylation de CD19

$m / s n^{\circ} 5$, vol 11, mai 95 sur plusieurs tyrosines permettant son association ultérieure à la PTK Lyn, d'une part, et la PI3K, d'autre part [23, 24] (figure 4). A la surface du lymphocyte B, CD19 fait partie d'un complexe comprenant trois autres molécules: CD21 (le récepteur de type 2 du complément, CR2), TAPA1 (targel of antiproliferative antibody ou CD81) et Leul 3 (leukocyte surface antigen) $[18,25]$. C'est sur l'expression de CD19 que repose la spécificité du complexe sur le lymphocyte B. En revanche, en l'absence de ligand connu de CD19, l'activation du lymphocyte B se fait de façon synergique sous l'influence de l'antigène (via le BCR) et des ligands de CD21 (iC3b, C3dg lié à l'antigène, CD23 membra- naire des cellules folliculaires dendritiques ou CD23 soluble) $\left(\mathrm{m} / \mathrm{s} n^{\circ} 5\right.$, vol 7, p. 486).

\section{Rétro-régulation de la réponse $B$}

Comme nous l'avons vu, CD19 peut transmettre un signal inhibiteur de la réponse $\mathrm{B}$ lorsqu'il est stimulé en absence de costimulation du récepteur de l'antigène [18]. Par ailleurs, l'addition de TGF $\beta$ ou le pontage des Fc $\gamma$ R (essentiellement Fc $\gamma$ RIIbl sur le lymphocyte B) inhibe la réponse à l'antigène. Bien que le pontage des Fc $\gamma$ RII n'affecte pas la phosphorylation des PTK associées au BCR, il entraîne une hyperphosphorylation de la p62 GAP-associated protein et inhi- 


\section{RÉFÉRENCES}

24. Tuveson DA, Carter RH, Soltoff SP, Fearon DT. CD19 of B cells as a surrogate kinase insert region to bind phosphatidylinositol 3-kinase. Science 1993; 260:986-9.

25. Bradbury LE, Kansas GS, Levy $S$ Evans RL, Tedder TF. The CD19/CD21 signal transducing complex of human $B$ lymphocytes includes the target of antiproliferative antibody-1 and Leu-13 molecules. Immunol 1992; 149: 2841-50.

26. Gottschalk AR, Joseph LJ, Quintans J Fc $\gamma$ RII cross-linking inhibits anti-Ig-induced egr-1 and egr-2 expression in BCLI. $J \mathrm{Immu}$ nol 1994; 152: 2115-22.

27. Clark EA, Ledbetter JA. How B and T cells talk to each other. Nature $1994 ; 367$. 425-8.

28. Linsley PS, Brady W, Grosmaire L, Aruffo A, Damle NK, Ledbetter JA. Binding of the $B$ cell activation antigen $B 7$ to CD28 costimulates $T$ cell proliferation and interleukin 2 mRNA accumulation. $\int$ Exp $\mathrm{Med}$ $1991 ; 173: 721-30$

29. Linsley PS, Brady W, Urnes M, Grosmaire LS, Damle NK, Ledbetter JA. CTLA-4 is a second receptor for the $B$ cell activation antigen B7. JExp Med 1991; 174: 561-9.

30. Lenschow DJ, Zeng Y, Thistlethwaite IR Montag A, Brady W, Gibson MG, Linsley PS, Bluestone JA. Long term survival of xenogeneic pancreatic islet grafts induced by CTLA4IG. Science 1992 ; 257: 789-95.

31. Boussiotis VA, Freeman GJ, Gribben JG Daley J, Gray G, Nadler LM. Activated human B lymphocytes express three CTLA4 counterreceptors that costimulate T-cell activation. Proc Natl Acad Sci USA 1993; 90 $11059-63$.

32. Armitage RI, Fanslow WC, Strockbine L Sato TA, Clifford KN, MacDuff BM, Anderson DM, Gimpel SD, Davis-Smith T, Maliszewski CR, Clark EA, Smith CA, Grabstein KH, Cosman D, Spriggs MK. Molecular and biological characterization of murine ligand for CD40. Nature 1992; 357: 80-2.

33. Jumper MD, Splawski JB, Lipsky PE Meek K. Ligation of CD40 induces sterile transcripts of multiple IgH chain isotypes in human B cells. I Immunol 1994; 152: 438-45.

34. Smith CA, Farrah T, Goodwin RG. The TNF receptor superfamily of cellular and viral proteins: activation, costimulation, and death. Cell 1994; $76: 959-62$.

35. Aversa G, Punnonen I, De Vries JE. The 26-kD transmembrane form of TNF $\alpha$ on activated $\mathrm{CD4}^{+} \mathrm{T}$ cell clones provides a costimulatory signal for human B cell activation.
36. Macchia D, Almerigogna $F$, Parronchi $P$, Ravina A, Maggi E, Romagnani S. Membrane TNF- $\alpha$ is involved in the polyclonal $B$ cell activation induced by $\mathrm{HIV}$-infected human T cells. Nature $1993 ; 363: 464-7$.

37. Poudrier J, Owens T. CD54/ICAM1 and major histocompatibility complex II signaling induces B cells to express IL2 receptors and complements Help provided through CD40 ligation. J Exp Med 1994; 179: 1417 27.

38. Liu Y], Oldfield S, MacLennan ICM Memory $\mathrm{B}$ cells in T-cell dependent antibody responses colonize the splenic marginal zones. Eur I Immunol 1988; 18: 355-62.

39. Moller P, Mielke B. Extrafollicular peri pheral B cells report. Leukocyles Typing $I V$ $1989 ; 213-5$.

40. Liu Y], Johnson GD, Gordon J, MacLennan ICM. Germinal centers in $T$ cell dependent antibody responses. Immunol Today $1992 ; 13: 17-21$

41. Kosco MH, Gray D. Signal involved in germinal center reactions. Immunol Rev $1992 ; 126: 63-76$.

42. Kepler TB, Perelson AS. Cyclic re-entry of germinal center $B$ cells and the efficiency of affinity maturation. Immunol Today 1993; $14: 412-5$

43. Gray D. Immunological memory. Annu Rev Immunol 1993; 11 : 49-77.

44. Pascual V, Liu Y], Magalski A, De Bouteiller O, Banchereau J, Capra JD. Analysis of somatic mutation in five $B$ cell subsets of human tonsil. J Exp Med 1994; 180 : 329-39.

45. Van Der Eertwegh AJM, Noelle RJ, Roy M, Shepherd DM, Aruffo A, Ledbetter JA, Boersma WJA, Claassen E. In vivo CD40 gp39 interactions are essential for thymus-
dependent humoral immunity. I. In vivo expression of $\mathrm{CD} 40 \mathrm{~L}$, cytokines and antibody production delineates sites of cognate $T$. B cell interactions. J Exp Med 1993; 178 : 1555-65.

46. Foy TM, Shepherd DM, Durie FH, Aruf fo A, Ledbetter A, Noelle RJ. In vivo CD40 gp39 interactions are essential for thymus-dependent humoral immunity. II. Prolonged suppression of the humoral immune responses by an antibody to the ligand for CD40, gp39. J Exp Med 1993; 178 : 1567-75.

47. Nonoyama S, Hollenbaugh D, Aruffo A Ledbetter JA, Ochs HD. B cell activation via CD40 is required for specific antibody production by antigen stimulated human $B$ cells. J Exp Med 1993; 178 : 1097-102. be l'expression des facteurs de transcription Egr-1 et Egr-2 (early growth response), normalement induits lors de la réponse antigénique [26]. Sur le lymphocyte $B$, les effets inhibiteurs du TGF $\beta$ aussi bien que ceux relayés par les Fc $\gamma$ RII peuvent être contrecarrés par l'ajout d'IL4.

\section{Molécules membranaires $d^{\prime}$ interaction T-B directe}

L'interaction T-B directe repose sur la présentation au lymphocyte T CD4 de peptides issus de l'apprêtement de l'antigène par le lymphocyte $B$. Les capacités de présentation du lymphocyte B sont induites par contact avec l'antigène qui augmente l'expression de molécules d'interaction déjà présentes (HLA de classe II, CD40, récepteur de l'IL4) et en induit de nouvelles (B7, récepteurs d'autres cytokines).

Le contact et la signalisation bidirectionnelle entre lymphocyte B et lymphocyte $\mathrm{T}$ dépendent de l'interaction peptide-HLA/TCR et de plusieurs couples de molécules dites accessoires, selon un processus très général caractéristique de l'interaction entre lymphocyte T CD4 et cellule présentatrice [27] (figure 5). Deux de ces couples ont été découverts récemment, sur la base de leur rôle dans la réponse $\mathrm{B}$.

B7 : d'un antigène d'activation $B$ à une famille de molécules d'interaction T-cellules présentatrices

L'avancée des connaissances sur B7 est exemplaire de l'évolution des idées en matière de coopérations lymphocytaires. B7 est longtemps resté une molécule d'activation $B$ en quête de son ligand. La démonstration d'une liaison B7/CD28 a éclairé le rôle de $\mathrm{B} 7$ dans la réponse $\mathrm{B}$ : l'apparition de B7 permet au lymphocyte $B$ activé d'amplifier la réponse de son partenaire $T$, par une voie particulièrement importante pour la potentialisation de la production des cytokines [28]. Le rôle de $\mathrm{B} 7$ dépasse la réponse $\mathrm{B}$. Son expression s'étend à l'ensemble des cellules présentatrices, et $\mathrm{B} 7$ est considéré comme l'inducteur d'un signal dit accessoire, essentiel à la réponse $\mathrm{T}$, et qui pourrait être une clé du "choix» entre réponse et anergie. De plus, B7 pour- 


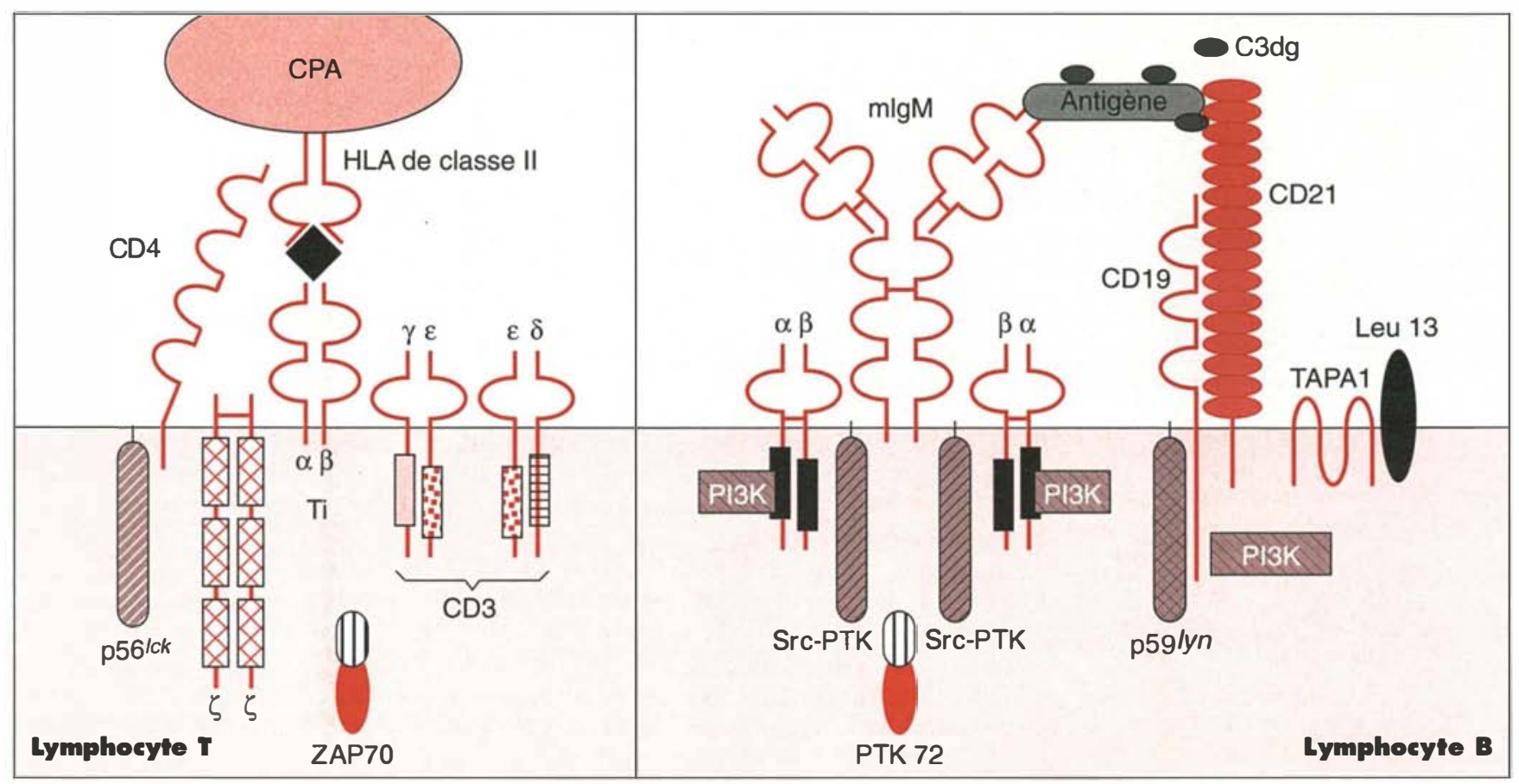

Figure 4. Le complexe CD19/CD21 comme corécepteur du BCR. L'antigène, sous forme complexée aux fragments du complément, peut se lier simultanément au complexe CD19/CD21 via le C3d,g et au BCR via l'antigène. Ce processus entraîne la stimulation du lymphocyte $B$ et une synergie entre les mécanismes de transduction liés au BCR et au complexe CD19/CD21 (voir figure 2). Une situation analogue est observée sur le lymphocyte $T$ où le peptide antigénique associé aux antigènes liés au CMH de classe II costimule le TCR et la molécule CD4.

rait également agir sur les lymphocytes T CD8 cytotoxiques, notamment par l'intermédiaire de son second ligand, la molécule CTLA-4 [29]. De fait, l'injection de CTLA-4 solubilisé, qui supprime la réponse anticorps, permet également le non-rejet de greffes [30]. Des données récentes suggèrent qu'au cours de la réponse B, CD28 et CTLA-4 interagissent préférentiellement avec deux molécules B7 différentes: B7.2 (CD86), dont le messager est présent au stade du lymphocyte B au repos, traduit précocement après l'activation et qui délivrerait via sa liaison à CD28 puis CTLA-4 un signal essentiel à l'induction de la réponse $\mathrm{T}$; B7.1 (CD80), absent des lymphocytes B au repos, apparaissant après 48 heures d'activation, contribuerait plutôt via son interaction avec CD28 et CTLA-4 à l'expansion clonale des lymphocytes $\mathrm{T}$ préalablement activés [31]. Une troisième molécule de la famille B7, la molécule B7.3 reconnue par l'anticorps $\mathrm{BBl}$ interviendrait aussi dans la régulation des interactions $\mathrm{T} / \mathrm{B}$ [31] selon des modalités qui restent à définir.

$\mathrm{m} / \mathrm{s} n^{\circ} 5$, vol. 11 , mai 95
CD40 : un récepteur essentiel de la coopération T-B

Les connaissances sur CD40, molécule présente sur le lymphocyte $B$ au repos, ont progressé dans plusieurs directions: (1) la caractérisation du ligand de CD40 (CD40-L), molécule d'activation précoce et transitoire des lymphocytes T [32] ; (2) les conséquences de l'interaction CD40/CD40$\mathrm{L}$, uniquement détectables en présence de cytokines: croissance de lymphocytes B en lignées et production d'immunoglobulines, commutation de classe $\left(m / s n^{\circ} 4\right.$, vol. $\left.9, p .456\right)$; (3) les conséquences moléculaires du signal CD40 : ouverture de l'ADN dans les régions promotrices des gènes de chaînes lourdes, préparant la recombinaison nécessaire à la commutation de classe [33].

Un autre enseignement apporté par le système CD40/CD40-L a été la mise en lumière de similitudes entre certains couples de molécules de membrane et des couples de cytokines/ récepteurs de cytokines. CD40 appartient à la famille des récepteurs des
TNF; CD40-L présente des homologies avec le TNF et, comme celui-ci, doit être sous forme trimérique pour exercer son activité [34]. Dans le même ordre d'idées, les lymphocytes $\mathrm{T}$ activés expriment la forme membranaire du TNF $\alpha$ qui peut intervenir comme activateur des lymphocytes B [35]. La dérégulation d'expression du TNF $\alpha$ membranaire pourrait jouer un rôle primordial dans l'hyperactivation polyclonale B et notamment celle observée chez des malades séropositifs pour le VIH [36].

Au cours de la réponse à un antigène thymo-dépendant, un «dialogue réciproque " s'instaure entre les couples B7/CD28 et CD40/CD40-L [27]. En effet, si le contact B7.2/CD28 induit une première phase d'activation $\mathrm{T}$ conduisant à l'expression de CD40-L et de CTLA-4, l'interaction CD40 $\mathrm{L} / \mathrm{CD} 40$ rend ainsi possible l'expression de nouvelles molécules B7 (B7.1 et B7.3) sur le lymphocyte B. Ces molécules entreront à leur tour dans des interactions avec CD28 et CTLA4 amplifiant ainsi l'activation des lymphocytes et stimulant la production 


\section{RÉFÉRENCES}

48. Foy TM, Laman JD, Ledbetter IA Aruffo A, Claassen E, Noelle RJ. gp39-CD40 interactions are essential for germinal center formation and the development of $B$ cell memory. J Exp Med 1994; 180: 157-63.

49. Gray D, Dullforce $\mathbf{P}$, Jainandunsing $\mathbf{S}$ Memory B cell development but not germinal center formation is impaired by in vivo blockade of CD40-CD40L interaction./ Exp Med 1994; 180: 141-55.

50. Emilie D, Fior R, Llorente L, Marfaing Koka A, Peuchmaur M, Devergne $\delta$, Jarrousse B, Wijdenes J, Boue F, Galanaud P Cytokines from lymphoid organs of HIV infected patients: production and role in the immune disequilibrium of the disease and in the development of B lymphomas. Immunol Rov 1994;140: 5-34.

51. Linsley PS, Wallace PM, Johnson J, Gibson MG, Greene JL, Ledbetter JA, Singh $\mathrm{C}$, Tepper MA. Immunosuppression in vivo by a soluble form of the CItA-4 T cell activation molecule. Science 1992; 257 : 792-5

52. Milich DR, Linsley PS, Hughes JL, Jones JE. Soluble CTLA-4 can suppress autoantibody production and elicit long term unresponsiveness in a novel transgenic model. I Immunol 1994; 153 : 429-34.

53. Damle NK, Klussman K, Linsley PS, Aruf fo A. Differential costimulatory effects of adhesion molecules B7, ICAM1, LFA3 and VCAM 1 on resting and antigen-primed $\mathrm{CD}^{+} \mathrm{T}$ lymphocytes. J Immunol $1992 ; 148$ : 1985-92.

54. Walter H, Schepsen S, Van Wauwe, De Boer M. Ligation of CD28 on resting T cells by its ligand $B 7$ results in the induction of both Th1 and Th2 type cytokines. Eur Cytokine Netw 1994; 5: 13-21.

55. NishiKawa $K$, Linsley PS, Collins AB, Stamenkovic I, McCluskey RT, Andres G. Effect of CTLA-4 chimeric protein on rat autoimmune anti-glomerular basement membrane glomerulonephritis. Eur J Immunol 1994 ; 24 : 1249-54.

56. Nickoloff BJ, Mitra RS, Lee K, Turka LA, Green J, Thompson C, Shimizu Y. Discordant expression of CD28 ligands, BB1 and $\mathrm{B} 7$, on keratinocytes in vitro and psoriatic cells in vivo. Am J Pathol 1993; 142 : 1029-40.

57. Guerder S, Picarella DE, Linsley PS, Flavell RA. Costimulator B7.1 confers antigen presenting cell function to parenchymal tissu and in conjonction with TNF $\alpha$ leads to autoimmunity in transgenic mice. Proc Natl Acad Sci USA 1994; 91 : 5138-42. de cytokines. D'autres couples de molécule comme CDlla/CD18CD54 favorisent la maturation des lymphocytes B sans être cependant indispensables à une réponse anticorps [37].

\section{Lymphocytes B mémoires et interac- tions cellulaires}

La réponse à un antigène TD conduit à la production de deux types de lymphocytes: les plasmocytes et les lymphocytes B mémoires. La réponse primaire a lieu dans les régions extrafolliculaires $T$ dépendantes des ganglions ou de la rate alors que la réponse secondaire va nécessiter la migration des lymphocytes dans les follicules où ils seront à l'origine des centres germinatifs [38, 39]. La formation de centres germinatifs est essentielle à une réponse secondaire puisque les lymphocytes vont y subir, après une première phase de prolifération, des étapes de commutations isotypiques, de mutations somatiques et de sélection des lymphocytes ainsi mutés au contact des cellules folliculaires dendritiques $[40,41]$. Plusieurs cycles successifs de mutations/ sélections auront lieu, conduisant à l'expression d'Ig présentant des régions $\mathrm{V}$ de forte affinité pour l'antigène [42]. Les lymphocytes $B$ mémoires issus de ces processus constituent une population hétérogène qui comprend: (1) les lymphocytes $\mathrm{B}$ mémoires des centres germinatifs (sIgD- ${ }^{-} \mathrm{CD}^{-} 3^{-}, \mathrm{CD} 44$ faible) qui conservent leur capacité de proliférer en présence d'antigène et assurent le renouvellement du pool de lymphocytes B mémoires, (2) les lymphocytes émigrant des centres germinatifs $\left(\mathrm{IgD}^{-}, \mathrm{CD}^{2} 3^{-}, \mathrm{CD}_{4} 4^{++}\right)$qui constituent un pool de lymphocytes mémoires circulants et sont à l'origine des lymphocytes mémoires non circulants de même phénotype présents dans les zones extrafolliculaires spléniques, ganglionnaires ou associées au tube digestif $[39,43,44]$.

Alors que les lymphocytes B mémoires folliculaires n'expriment plus CD22, ceux de la zone marginale splénique sont fortement CD22 ${ }^{+}$[39]. Il faut souligner que la molécule CD45R0, ligand de CD22, n'est exprimée que sur les lymphocytes $\mathrm{T}$ mémoires [17, 27]. Les interactions entre CD40, présent sur tous les lym- phocytes B, à l'exception des plasmocytes, avec son ligand (CD40-L) sont nécessaires à l'induction de la réponse primaire, à la migration des lymphocytes B dans les centres germinatifs, au développement de centres germinatifs, à la commutation isotypique et à la survie des lymphocytes B convenablement mutés [45-48] $(\mathrm{m} / \mathrm{s}$ $n^{\circ} 4$, vol. 9, p. 456.). Les lymphocytes $\mathrm{B}$ mémoires résidents expriment la molécule CD40 et les données in vitro suggèrent que le contact avec son ligand intervient dans leur différenciation [49]. En revanche, la différenciation en plasmocytes est sous le contrôle de signaux différents de CD40 tels que IL2 ou CD23s + IL $1 \alpha$ dans les centres germinatifs [40, 43] et CD44 ou IL6 dans la moelle [43, 50]. Au contraire de CD40, la réactivité pour B7 est restreinte aux centres germinatifs et son rôle au cours des différentes étapes conduisant au lymphocyte B mémoire est encore mal connu [39]. Dans des modèles animaux, l'utilisation de molécules chimères CTLA4-Ig a cependant bien établi que les interactions de B7 avec ses ligands sont essentielles à une réponse primaire et secondaire [51] et peuvent contrôler la production d'anticorps auto-immuns [52]. Les interactions B7-CD28 semblent jouer un rôle prépondérant dans la stimulation des lymphocytes $\mathrm{T}$ mémoires (CD45RO), notamment dans la production d'IL4 par ces cellules [53, 54]. Au contraire, l'activation des lymphocytes $T$ naïs requiert des interactions impliquant d'autres molécules d'interactions LFAl et VLA4 [53].

Molécules d'interaction T-B : du fondamental à la clinique

Les modèles animaux ont permis de démontrer l'importance du signal relayé par les molécules $\mathrm{B} 7-\mathrm{CD} 28$ ou B7-CTLA-4 dans des réponses humorales ou cellulaires normales. Ces modèles permettent aussi de tester l'utilisation potentielle, comme outil thérapeutique, de protéines solubles chimères obtenues par fusion des parties extracellulaires des ligands de B7 et les fractions Fc des Ig circulantes. Les molécules CTLA4-Ig se sont ainsi révélées des outils précieux pour inhiber la production d'autoanticorps $[51,52]$, le développement de 


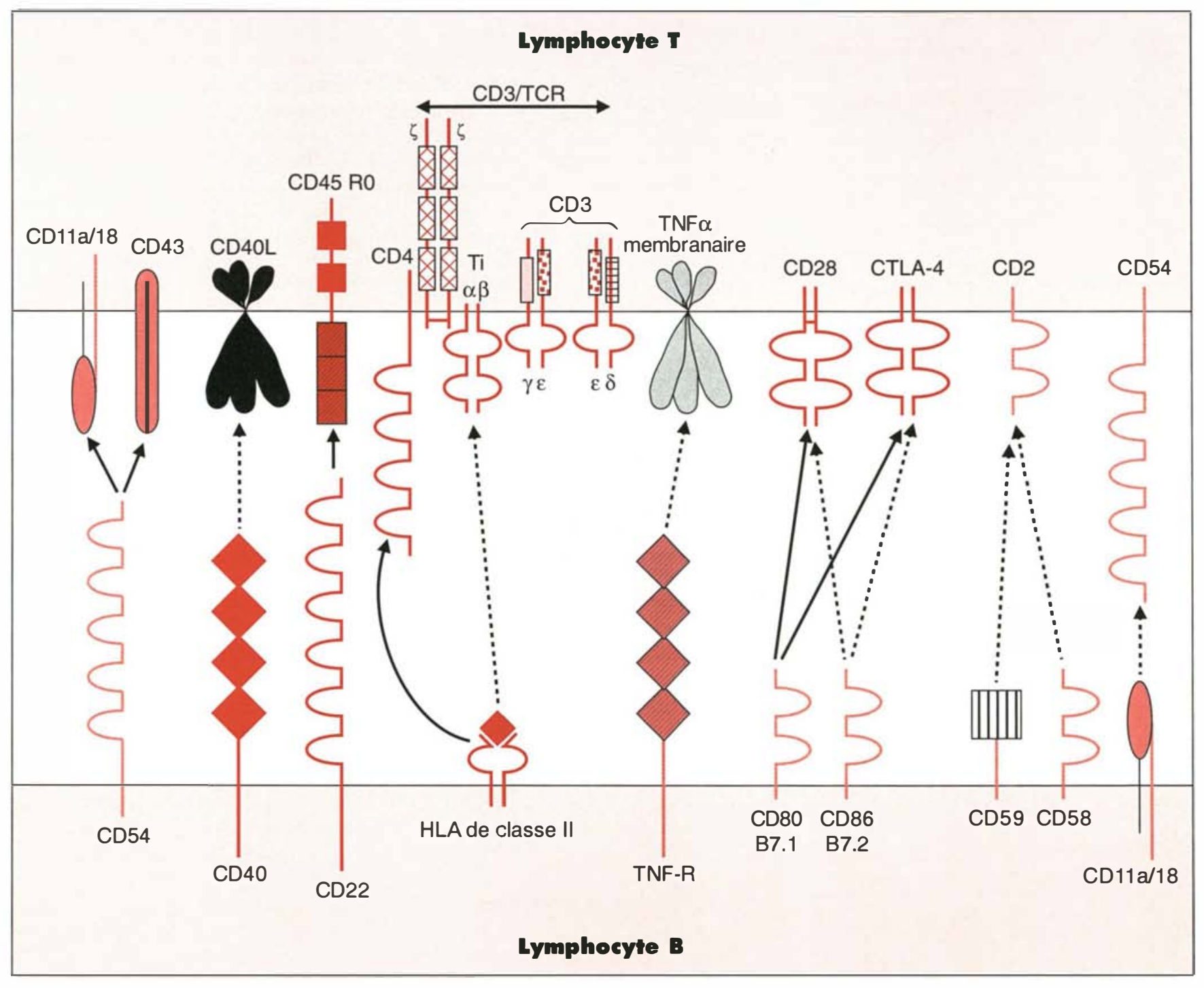

Figure 5. Molécules d'interactions B-T. Le lymphocyte $B$ exprime différents types de molécules d'interactions $B$ - $T$ : (1) I'antigène pan-B CD40 ou les antigènes d'activation B7.2 (CD86), B7.1 (CD80) et B7.3 qui sont également exprimés par la majorité des cellules présentatrices de l'antigène ; et (2) les molécules d'adhérence (CD54, CD11a/CD18, CD58), dont la distribution tissulaire est plus large que celle de CD40 ou CD80. Le lymphocyte B au repos exprime le BCR, $C D 22$ et CD40 mais n'interagit pas avec le lymphocyte $T$. Une fois activé par l'antigène, le lymphocyte $B$ accroît l'expression des molécules CD40, CMH de classe Il et induit celle des molécules B7.2, CD11a/CD18, CD54 et du TNFaR (p75). L'activation du lymphocyte $T$ par les cellules présentatrices de l'antigène ou par le lymphocyte $B$ stimulé permet l'expression du ligand de CD40, de CTLA-4, et de TNF $\alpha$ membranaire. A terme, l'ensemble des couples CD40/CD40-L, B7-CD28 et CTLA-4, CD11a/CD18-CD54, CD54-CD11a/CD18 interviennent dans la régulation de la différenciation lymphocytaire $B$. De plus, les lymphocytes $T$ mémoires (CD45RO) pourront établir des interactions avec les lymphocytes $B$ via CD22. 


\section{RÉFÉRENCES}

58. Harlan DM, Hengartner $H$, Huang ML, Kang YH, Abe R, Moredith RW, Pircher $\mathrm{H}$ Gray GS, Ohashi PS, Freeman GJ, Nadler LM, June CH, Aichele P. Mice expressing both B7.1 and viral glycoprotein on pancreatic B cells along with glycoprotein specific transgenic $T$ cells develop diabetes due to a breakdown of $\mathrm{T}$ lymphocyte unresponsiveness. Proc Nall Acad Sci USA 1994; 91 : 3137-41.

59. Nasir A, Ferbel B, Salminen $W$, Barth RK, Gaspari AA. Exaggerated and persistent cutaneous delayed type hypersensivity in transgenic mice whose epidermal keratinocytes constitutively express B7.1 antigen. $J$ Clin Invest 1994; 94 : 892-8.

60. Turka LA, Linsley PS, Lin H, Brady W, Leiden JM, Wei RQ, Gibson ML, Zheng XG, Myrdal S, Gordon D, Bailey T, Bolling SF, Thompson CB. T cell activation by the CD28 ligand B7 is required for cardiac allograft rejection in vivo. Proc Natl Acad Sci USA $1992 ; 89: 11102-5$.

61. Li Y, McGowan P, Hellström I, Hellström KE, Chen L. Costimulation of tumor reactive $\mathrm{CD} 4^{+}$and $\mathrm{CD} 8^{+} \mathrm{T}$ lymphocytes by $B 7$, a natural ligand for $C D 28$, can be used to treat established mouse melanoma. $J$ Immunol 1994; 153: 421-8.

62. Ramarathinam L, Castle M, Wu Y, Liu Y. $\mathrm{T}$ cell costimulation by $\mathrm{B} 7 / \mathrm{BB}$ induces CD8 T-cell dependent tumor rejection: an important role of $\mathrm{B} 7 / \mathrm{BB} 1$ in the induction, recruitment and effector function of antitumor T cells. J Exp Med 1994; 179: 1205-14.

63. Baskar S, Ostrand-Rosenberg S, Nabavi N, Glimcher L. Constitutive expression of B7 restores immunogenicity of tumor cells expressing truncated MHC class II molecules. Proc Natl Acad Sci USA 1993; 90 : 701521.

64. Poo WJ, Conrad L, Janeway CAJ. Receptor directed focusing of lymphokine release by helper T cells. Nature $1988 ; 332$ : 378-80.

65. Kühn R, Rajewsky K, Müller W. Generation and analysis of interleukin 4 deficient mice. Science 1991 ; 254: 707-10.

66. Minty A, Chalon P, Derocq JM, Dumont X, Guillemot JC, Kaghad M, Labit C, Leplatois P, Liauzun P, Miloux B, Minty C, Casellas P, Loison G, Lupker J, Shire D, Ferrara $P$, Caput D. Interleukin-13 is a new human lymphokine regulating inflammatory and immune responses. Nature 1993; 362: 248 - phénomènes auto-immuns [55-58] ou d'hypersensibilité retardée [59] et de réponses cytotoxiques délétères comme dans le cas d'allogreffes [30, $60]$. Les données concernant la survenue de maladies auto-immunes soulignent le rôle important de facteur permissif que joue le contexte immunologique (production de cytokines, présence d'anticorps ou de virus) dans lequel se situent les cellules $\mathrm{B} 7^{+}[56-58]$. Les résultats obtenus chez l'animal avec CTLA4-Ig suggèrent une grande spécificité d'action des protéines de fusion vis-àvis du clone de lymphocytes primés par l'antigène sans anergie des autres clones. C'est pourquoi, l'utilisation en clinique de ces outils humanisés semble du domaine du futur proche. Par ailleurs, le transfert de gène B7 dans les cellules tumorales s'est révélé très efficace dans le rejet de mélanomes et sarcomes murins [61-63]. Bien que ces résultats soient prometteurs, de nombreux obstacles restent à franchir avant d'envisager l'utilisation en thérapie humaine de cellules modifiées dans les gènes codant pour ces molécules d'interactions T-B.

L'injection de cellules syngéniques exprimant CD40L ou d'une protéine de fusion correspondant au CD40-L soluble constituerait une thérapie de choix en cas de syndrome hyper-IgM $\left(m / s n^{\circ} 4\right.$, vol. 9 p. 456) ou de déficits immunitaires communs variables. En effet, pour ces deux types de déficits immunitaires, l'expression d'un CD40-L anormal conduit à une perturbation de la réponse anticorps qui est corrigée, in vitro, par l'ajout de CD40-Ig. Les études chez l'animal manquent encore pour s'assurer de l'efficacité et de la non-toxicité de ce traitement.

\section{Le rôle des cytokines}

Les conditions de l'engagement des interleukines dans le processus de réponse lymphocytaire $\mathrm{B}$ sont mises en place grâce à l'activation du lymphocyte B par l'intermédiaire du BCR et à l'échange de signaux bidirectionnels associés à l'interaction liée. Les signaux délivrés au lymphocyte T CD4 par l'intermédiaire du complexe TCR/CD3 et de CD28 activent les gènes de ces médiateurs et augmentent la stabilité de leurs ARNm. La production des cytokines qui en résulte a lieu dans le microenvironnement immédiat du lymphocyte $\mathrm{B}$ activé, grâce à une orientation de l'appareil de Golgi du lymphocyte T4 au pôle cellulaire où sont regroupées les molécules d'interaction liée T-B [64]. L'expression des récepteurs de forte affinité pour les cytokines est induite (IL2R, IL6R, IL5R) ou accrue (IL4R) par l'activation du lymphocyte $B$ par l'antigène. Ainsi, les modifications membranaires des lymphocytes B et $\mathrm{T}$ et le déclenchement de la synthèse des interleukines par les lymphocytes $\mathrm{T}$ amplificateurs sont-ils étroitement coordonnés, ce qui soustend certaines propriétés essentielles de la réponse anticorps dépendante des lymphocytes $\mathrm{T}$ : elle peut être déclenchée par de très faibles concentrations d'antigène; les lymphocytes T CD4 peuvent exercer leur effet auxiliaire par l'intermédiaire d'interleukines produites en très faible quantité; ces médiateurs non spécifiques n'altèrent pas la spécificité de la réponse pour l'antigène.

Il est impossible de rendre compte de l'ensemble des données accumulées au cours des dix dernières années sur les effets des interleukines, isolées et en association, aux différentes étapes de la réponse $\mathrm{B}$, en conjonction avec les multiples signaux d'activation membranaire susceptibles d'intervenir dans celle-ci. Mais les données apportées par ces expériences et les enseignements fournis par les souris transgéniques ou chez lesquelles certains gènes ont été invalidés permettent d'avoir une vision plus synthétique du rôle des interleukines dans la réponse $B$.

Les cytokines sont strictement nécessaires à la production des immunoglobulines

Même en présence de signaux antigéniques et d'une interaction T-B liée, les lymphocytes B sont incapables de produire des anticorps en absence d'interleukines. L'utilisation de membranes fixées préparées à partir de clones $\mathrm{T}$ ou de lymphocytes $\mathrm{T}$ activés, ou la stimulation par l'intermédiaire de CD40 (anticorps antiCD40 ou ligand trimérique de CD40) ont permis de préciser le rôle prépondérant de l'IL2, de l'IL4, et de l'IL10 dans la production d'anticorps. Chez l'homme, l'IL4 (unique- 


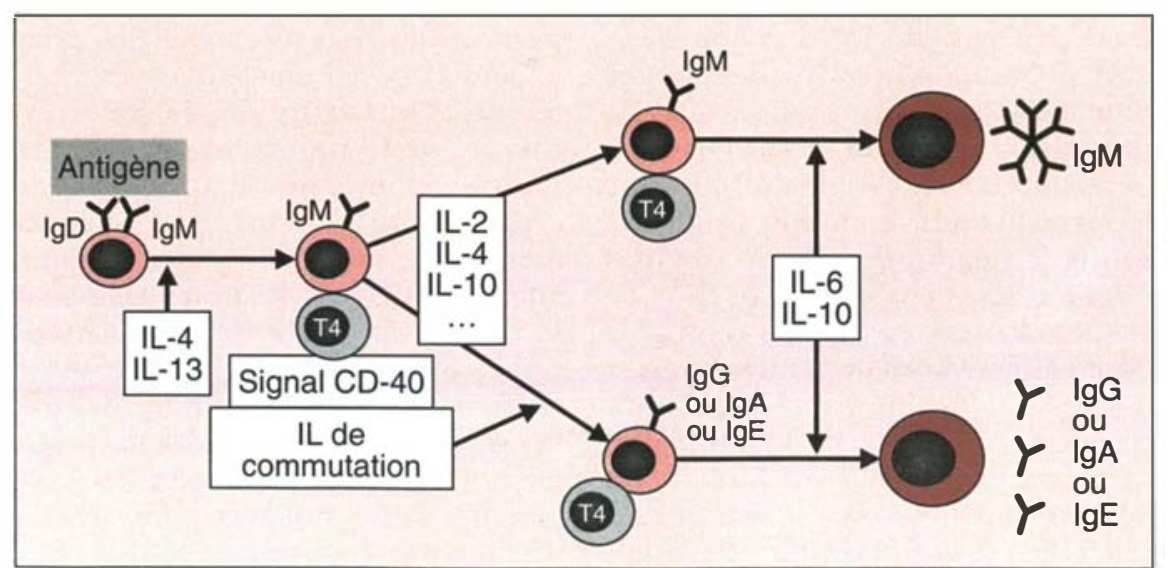

Figure 6. Les interleukines de la réponse lymphocytaire B. Le lymphocyte $B$ naïf $\left(s / g M^{+}, s / g D^{+}\right)$, stimulé par l'antigène, perd ses $\lg D$ membranaires, acquiert les molécules B7 et devient capable d'interagir avec les lymphocytes $T$ activés exprimant CD40-L, CD28 et CTLA4. Les interactions entre B7 et ses ligands soutiennent l'activation du lymphocyte $B$ et la prolifération $T$ via la production d'IL2. Les interactions CD40/CD40-L sont décisives pour ces étapes et pour les événements précoces de commutation. En fonction de l'environnement immédiat du lymphocyte $B$, différents types de cytokines sont majoritairement présents et accompagnent la commutation (IL2, IL4, IL 13, IL 10, TGFB) et la différenciation (IL6, IL 10) du lymphocyte B vers la production des divers isotypes.

ment en combinaison avec le signal CD40/CD40-L) contrôle l'orientation de la recombinaison des lymphocytes $\mathrm{B}$ sIgM+ en lymphocytes producteurs d'IgE (et d'IgG4) en sélectionnant directement les régions promotrices correspondantes [33]. L'observation que l'IL4 seule ou le signal CD40 seul sont incapables d'induire de tels phénomèmes de recombinaison suggère une régulation très stricte de la production des IgE et IgG4. Le rôle prépondérant de l'IL4 dans la production d'IgE est encore souligné par l'absence d'IgE chez les souris dont le gène de l'IL4 a été invalidé, et ce, même après infection par des nématodes [65]. Chez l'homme, il a été récemment démontré qu'in vitro l'IL13 pouvait également orienter la commutation des lymphocytes B naïfs vers la production d'IgE et d'IgG4 par un mécanisme indépendant de l'IL4 [66].

Au contraire de ce qui se passe pour la production des IgE, l'addition de CD40 seul suffit à induire les premiers événements de recombinaison indispensables à la production des autres isotypes (IgA ou $\operatorname{IgG1}, 2$ et 3) $\mathrm{m} / \mathrm{s} n^{\circ} 5$, vol. 11 , mai 95 kine a été invalidé n'ont pas de déficit global de la production des anticorps [65]. L'IL13 possède certains des effets d'activation précoce du lymphocyte B: elle augmente l'expression des IgM de membrane, et celle des antigènes HLA de classe II, CD72 et CD71. En revanche, l'IL13 est sans effet sur l'expression de la molécule CD40 et n'induirait l'expression de CD23 que sur certains lymphocytes B $[70,71]$.

\section{Certaines cytokines potentialisent la} différenciation terminale

La production des immunoglobulines par les lymphocytes B différenciés est amplifiée par l'IL6 et l'IL10 $\left(m / s n^{\circ} 4\right.$, vol. 9, p.453). L'IL10 permet au lymphocyte B activé de se différencier cytologiquement en plasmocyte (figure 6). Il est intéressant de souligner que l'IL6 et l'IL10 peuvent être produites en quantité importante par des cellules non-T, ce qui peut jouer un rôle à certaines étapes de la réponse ou intervenir dans certaines situations pathologiques [50]. Ainsi, le fort taux de sécrétion d'immunoglobulines des plasmocytes de la moelle osseuse est maintenu de façon indépendante des cellules T par l'IL6 (produit par les cellules stromales) et par un signal passant par CD44 (vraisemblablement fourni par la matrice extracellulaire de la moelle osseuse).

\section{Conclusions} l'IL5, amplifient la réponse de lymphocytes B commutés $\left(\operatorname{Ig} \mathrm{A}^{+}\right)(\mathrm{m} / \mathrm{s}$ $n^{\circ} 10$, vol 6, p. 954).

\section{Certaines cytokines amplifient les} étapes précoces d'activation

Les lymphocytes B au repos expriment des récepteurs de l'IL-4, et cette interleukine induit ou augmente l'expression d'une série de molécules importantes pour la réponse B (IgM de membrane, produits de classe II du CMH, CD40, CD23, CD72) [68] ( $m / s n^{\circ} 10$, vol. 6, p. 946) (figure 6). Plus récemment, il a été montré que l'IL4 pouvait induire l'expression des molécules B7.2 et B7.1 sur des lymphocytes B en l'absence de contact avec l'antigène [69]. Néanmoins, l'IL-4 n'est pas indispensable au déclenchement de la réponse $B$, puisque les souris dont le gène de cette interleu-
Des progrès spectaculaires dans la compréhension des réponses immunes normales et surtout pathologiques ont été obtenus grâce aux souris déficientes ou transgéniques pour un de surface lymphocytaires. Malgré ces progrès, la réponse du lymphocyte B à l'antigène reste un phénomène complexe où vont intervenir son état d'activation et/ou de différenciation, sa capacité d'interagir avec les cellules T et de répondre aux différents médiateurs solubles produits par les cellules $\mathrm{T}$ et non-T (figure 6). Le type de cellules non- $T$, présentatrices de l'antigène, ainsi que la nature de cet antigène (parasites, virus, protéines) vont influer sur l'émergence d'un type majoritaire d'effecteurs cellulaires T helpers de type Th1(IL2, IFN $\gamma$ ) ou Th2 (IL4, IL5, IL6, IL10, IL3). Les interleukines gène d'interleukine ou de molécules 


\section{RÉFÉRENCES}

67. Defrance $T$, Vanbervliet $B$, Brière $F$, Durand I, Rousset F, Banchereau I. Interleukin 10 and transforming growth factor $\beta$ cooperate to induce anti-CD40-activated naive human $B$ cells to secrete immunoglobulin A. I Exp Med 1992; 175: 671-82.

68. Banchereau I. Interleukine-4. médecine/ sciences $1990 ; 6: 946-53$

69. Stack RM, Lenschow DI, Gray GS, Bluestone JA, Fitch TW. IL4 treatment of small splenic B cells induces costimulatory molecules B7-1 and B7-2. I Immunol 1994; 152: 5723-33.

70. Zurawski G, De Vries JE. Interleukin 13 an interleukin 4like cytokine that acts on monocytes and B cells, but not on T cells. Immunol Today 1994; 15: 19-26.

71. Minty A. L'interleukine 13: une nouvelle pièce dans le puzzle immunitaire. méderine/sciences $1994 ; 10: 884-8$.

72. Romagnani S. Human Thl and Th2 subsets: "Eppur si muove". Eur Cylokine Vetw $1994 ; 5: 7-12$.

73. De France $T$, Vanbervliet B, Aubry JP, Banchereau J. Interleukin 4 inhibits the proliferation but not the differentiation of activated human B cells in response to IL2. I Exp Med 1988; 168: 1321-37.

74. Karray S, Dautry-Varsat A, Tsudo M Merle-Beral H, Debré P, Galanaud P. IL4 inhibits the expression of high affinity IL2 receptors on monoclonal human B cells. Immunol 1990; 145: 1152-8.

75. Llorente L, Mitjavila F, Crevon MC: Galanaud $P$. Dual effects of interleukin 4 on antigen-activated human $B$ cells: induction of proliferation and inhibition of IL.2-dependent differentiation. Eur I Immunol 1990; $20: 1887-92$

76. Kishimoto T, Taga T, Akira S. Cytokine signal transduction. Cill 1994; 76:25.3-62.

77. Hunter T. Cytokine connections. Nalure $1993 ; 366: 1146$

78. George A, Rath S, Scroff K, Wang M, Durdik JM. Ligation of CD 45 on B cells can facilitate production of secondary Ig isotypes. I Immunol 1994; 152: 1014-21.

79. June CH, Bluestone JA, Nadler LM, Thompson $\mathrm{CB}$. The $\mathrm{B} 7$ and $\mathrm{CD} 28$ recepto

produites par les Th2 expliquent le rôle prépondérant de cette population dans la différenciation $\mathrm{B}$ et la production d'IgE, IgA et d'IgG4. La population Th1, essentielle au développement d'une immunité cellulaire, soutient néanmoins la production d'IgM, d'IgG2 et 3 [72]. Chacune de ces populations règle l'expansion de la population réciproque à travers la production d'IFN $\gamma$ (inhibant l'émergence d'effecteurs Th2) ou d'IL4 (inhibant l'émergence d'effecteurs Thl) selon des mécanismes bien documentés [72]. Des effets antagonistes des interleukines de type Th1 ou Th2 sur les lymphocytes B sont aussi observés. Ainsi, l'IFN $\gamma$ inhibe certains eff ets de l'IL4 sur les lymphocytes B au repos. A l'inverse, l'IL4 peut inhiber la prolifération dépendante de l'IL2 de lymphocytes B normaux activés ou de certaines cellules leucémiques B [7375]. Les mécanismes qui sous-tendent ces antagonismes commencent à être compris grâce aux progrès décisifs dans le domaine de la transmission du

\section{Summary}

Antibody production : regulation by cytokines and T-B interactions

In response to antigenic stimulation, B lymphocytes differentiate into antibody producing cells or into memory cells. The specific B cell receptor (BCR) is composed of membrane immunoglobulin (Ig), acting as a ligand subunit, and of invariant heterodimers $(\alpha / \beta)$ required for stable membrane BCR as well as for interaction with cytoplasmic signalling molecules. $\alpha$ and $\beta$ chains, linked to different proximal effector enzymes (Src-PTK, PTK 72 and PI3K), deliver synergistic activation signals to the B cells. Co-receptor molecules (CD19/CD21 complex and CD22 molecule) amplify the antigenic signal and may prevent low efficiency triggering through the BCR. Antigen-induced BCR stimulation results in the expression of new surface molecules, the production of cytokines and the capacity to present antigen fragments bound to the MHC class II. To progress in their differentiation process, additional signals must be provided to activated $B$ cells through direct T-B

\section{TIRÉS À PART}

Y'. Richard

signal en aval des récepteurs des interleukines 2 et 4 , d'une part, et des interférons, d'autre part [76, 77]. Si les cytokines sont indispensables à une réponse humorale, la spécificité de cette réponse est assurée par le contact avec l'antigène lors duquel la costimulation ria CD19, CD22 ou CD45 peut se révéler essentielle $[27,78]$. Les interactions B7-CD28, B7-CTLA4 et CD40-('D40-L constituent une deuxième phase critique qui prévient l'anergie des clones $\mathrm{B}$ et $\mathrm{T}$ sélectionnés par l'antigène et induit la synthèse des cytokines par les lymphocytes $\mathrm{T}[79]$. L'ensemble de ces travaux sur la réponse humorale souligne l'intérêt de combiner les données de la biologie cellulaire et moléculaire à celles obtenues grâce aux modèles animaux (souris transgéniques, invalidation de gènes, ou souris SCID) et à la pathologie humaine

interactions and by cytokines secreted by activated $\mathrm{T}$ cells. The former involves integrins and selectins but also more specific ligand sets such as CD40/CD 40-L and B 7/CD28/ CTLA-4 respectively. The CD40/ CD40-L complex plays a key role in B cell switching and in the selection process leading to high affinity antibody producing cells. In contrast, B7CD28/CTLA-4 interactions seem essential to fully achieve $\mathrm{T}$ cell activation and interleukin-dependent $T$ cell expansion. An efficient humoral response also requires the secretion of Th- 2 cytokines by activated CD4 T cells. These cytokines act at different levels of the $B$ cell maturation in sustaining early B cell activation (IL4, IL13), isotype switching (IL4, IL5, IL13) or plasma cell differentiation (IL6, IL10). In this issue, we focus our attention on some crucial events of the B cell differentiation : (1) BCR signalling, (2) critical pairs of molecules involved on B-T interactions and (3) cytokines produced in the vicinity of B cells. 